\title{
Carnival and Energy Drinks: a Dangerous Combination to the Heart
}

\author{
Claudio Tinoco Mesquita ${ }^{1,2}$ \\ Universidade Federal Fluminense, ${ }^{1}$ Niterói, RJ - Brazil \\ Hospital Pró-Cardíaco, ${ }^{2}$ Rio de Janeiro, RJ - Brazil
}

Everything being a constant carnival, there is no carnival left.

Victor Hugo

Every year, millions of people of different ages and origins go to the streets in many countries around the world to celebrate carnival (Figure 1). In Brazil, the most popular carnival celebrations and parades take place in the city of Rio de Janeiro and in the Brazilian states of Bahia and Pernambuco. Rio de Janeiro's carnival alone drew more than 5 million people in the last years. One of the most common activities during carnival is taking part in the Samba Parade, a beautiful festival where people dance on the streets.

Samba dance requires vigorous and varied movements that can promote happiness and intense chronotropic response. One study demonstrated that during samba sessions, individuals can reach $60-90 \%$ of maximal heart rate predicted for age at $86 \%$ of time. ${ }^{1}$ Drinking alcohol is also very frequent during carnival, and its combination with energy drink (ED) intake has increased lately. And what would be the effects of this combination to the heart of people that want to celebrate this festivity?

Drinking is associated with atrial fibrillation (AF) in a situation called "Holiday Heart Syndrome". Binge drinking and even mild-to-moderate alcohol (seven drinks per week or more) increases the incidence of AF. ${ }^{1}$ Some studies have shown that the use of other substances associated with binge drinking, such as the recreational use of marijuana, may contribute to the increase in AF incidence. In a recent

\section{Keywords}

Carnival; Brazil; Dancing/trends; Music; Alcoholic Beverages; Cannabis; Atrial Fibrillation; Cafeine/adverse effects; Hospitalization; Arrhythmias, Cardiac. study, Desai et al. ${ }^{2}$ observed that $2.7 \%$ of recreational marijuana users developed arrhythmia with a steadily increasing trend from 2010 through 2014, and that AF was the most common subtype of arrhythmia among hospitalized marijuana users. ${ }^{2}$ The association of alcohol and marijuana should be greatly avoided because it doubles the odds of drunk driving, negative social consequences, and harms to self besides cardiac adverse effects. ${ }^{3}$

Energy drinks are legally allowed and can even be sold in schools. The marketing for ED consumption is targeted toward young adults aged between 18 and 34 years, and this strategy succeeded because EDs have been one of the fastest growing segments in the beverage industry. ${ }^{4}$ These drinks can have very high amounts of caffeine and other "energy-boosting" additives that have been linked with many reports of atrial and ventricular arrhythmias. ${ }^{1}$ In addition to their proarrhythmic effects, the consumption of EDs is associated with significant hemodynamic overload. Grasser et al. ${ }^{5}$ demonstrated that the ingestion of one can $((355-\mathrm{mL})$ of a sugar-sweetened ED resulted in an augmented workload to the heart as evidenced by elevated blood pressure, heart rate, cardiac output, and double product values. ${ }^{5}$

The hallmark feature of EDs is their high caffeine content. Caffeine is a methylxanthine alkaloid that stimulates the central nervous system. Caffeine has a half-life of $5.7 \mathrm{~h}$, nearly $100 \%$ bioavailability, and its maximum concentrations are reached within one hour of consumption. ${ }^{6}$ Caffeine activates the sympathetic nervous system and can act as an antagonist of the neuromodulator adenosine leading to elevations in blood pressure. It elevates the sinus rate by sympathomimetic effects mediated by phosphodiesterase inhibition and raises cytoplasmic calcium. ${ }^{6}$ ED ingestion has been associated with arrhythmias even in patients with structurally normal hearts. Fletcher et al. ${ }^{7}$ compared the effects of caffeine alone and EDs in healthy volunteers and demonstrated 


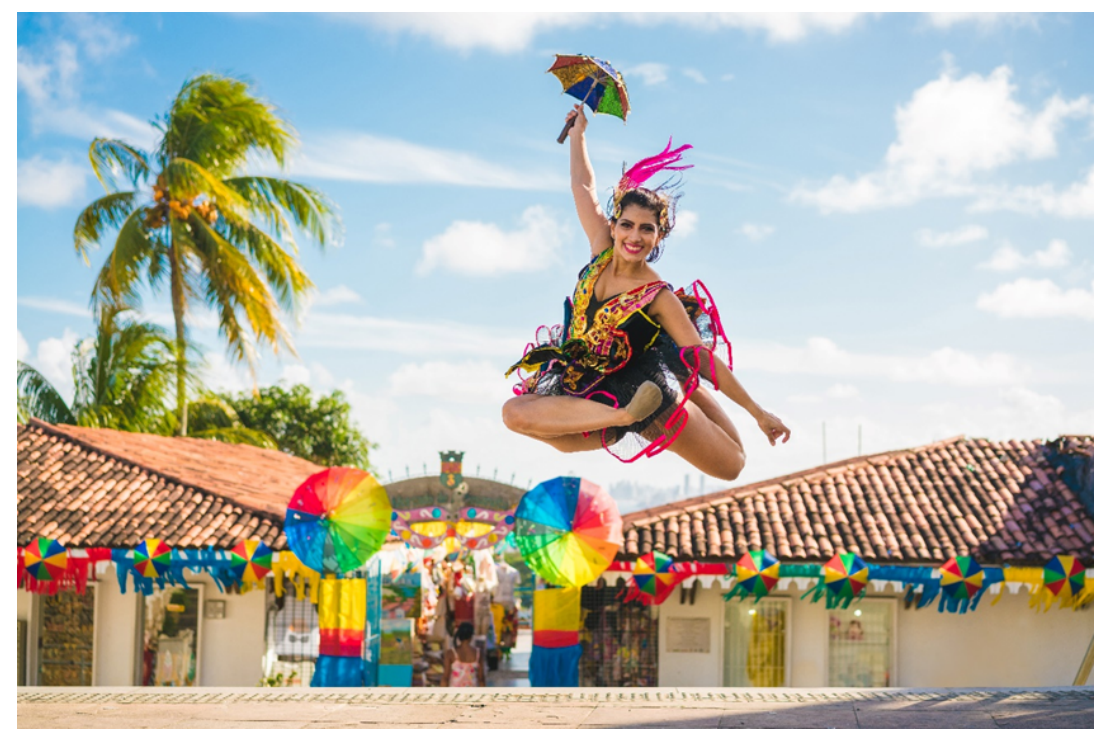

Figure 1 - Brazilian carnival. Women wearing carnival costumes and dancing in Olinda, Pernambuco, Brazil.

that the corrected QT interval and systolic blood pressure were significantly higher following high-volume ED consumption when compared with caffeine alone. ${ }^{7}$ Patients with congenital long QT syndrome should be strongly advised not to ingest EDs because dangerous QTc prolongation of $>50 \mathrm{~ms}$ following ED consumption has been reported. ${ }^{8}$ Although there is no clearly defined threshold for ED use, the International Society of Sports Nutrition recommends that patients with pre-existing cardiovascular conditions who are taking medications that may be affected by caffeine and other stimulants refrain from EDs, and they warn that more than one ED/day, even in healthy individuals, may be harmful. ${ }^{9}$

Celebrating carnival is easy, fun and cheap. The potential risks of combining ED and alcohol or illicit drugs are high, and patients should be advised of this. Also, the intake of EDs alone can increase the risk of cardiac adverse effects and should be done with moderation. One of the best things in life are good memories and having a cardiac complication during holidays is one those nobody would like to have.

\section{References}

1. Voskoboinik A, Prabhu S, Sugumar H, Kistler PM. Effect of Dietary Factors on Cardiac Rhythm. Am J Cardiol. 2018;122(7):1265-71.

2. Desai R, Patel U, Deshmukh A, Sachdeva R, Kumar G. Burden of arrhythmia in recreational marijuana users. Int J Cardiol . 2018;264:91-2.

3. Meenakshi S. Subbaraman WCK. Simultaneous vs. concurrent use of alcohol and cannabis in the National Alcohol Survey. Alcohol Clin Exp Res. 2016;39(5):872-9.

4. Grasser EK, Miles-Chan JL, Charrière N, Loonam CR, Dulloo AG, Montani J-P. Energy Drinks and Their Impact on the Cardiovascular System: Potential Mechanisms. Adv Nutr An Int Rev J. 2016;7(5):950-60.

5. Grasser EK, Yepuri G, Dulloo AG, Montani JP. Cardio- and cerebrovascular responses to the energy drink Red Bull in young adults: a randomized cross-over study. Eur J Nutr. 2014;53(7):1561-71.

6. Voskoboinik A, Kalman JM, Kistler PM. Caffeine and Arrhythmias: Time to Grind the Data. JACC Clin Electrophysiol 2018;4(4):425-32.

7. Fletcher EA, Lacey CS, Aaron M, Kolasa M, Occiano A, Shah SA. Randomized controlled trial of high-volume energy drink versus caffeine consumption on ECG and hemodynamic parameters. J Am Heart Assoc 2017;6(5):1-8.

8. Gray B, Ingles J, Medi C, Driscoll T, Semsarian C. Cardiovascular Effects of Energy Drinks in Familial Long QT Syndrome : A Randomized CrossOver Study. Int J Cardiol. 2017;231:150-4.

9. Campbell B, Wilborn C, La Bounty P, Taylor L, Nelson MT GM, Ziegenfuss TN,et al. International Society of Sports Nutrition position stand: energy drinks. J Int Soc Sport Nutr. 2013;10(1):1-20. 